\title{
Integrating Yoga Asanas in a Movement Science Course
}

\author{
Ulrika Aasa ${ }^{1}$, Tobias Sundberg ${ }^{2}$ and Sofia Bergström ${ }^{3}$ \\ ${ }^{1}$ Umeå University, Umeå, Sweden \\ ${ }^{2}$ Karolinska institutet, Stockholm, Sweden \\ ${ }^{3}$ Patanjali Yoga Teacher, Sweden
}

Submission: April 19, 2017; Published: June 27, 2017

*Corresponding author: Ulrika Aasa, Umeå Universitet, Enheten för fysioterapi, Vårdvetarhuset, Umeå, Sweden, Email: mailto:ulrika.aasa@umu.se

\section{Opinion}

In Sweden, shoulder pain is the third most common musculoskeletal consultation in primary care and second most common cause of referrals to orthopedic and sports medicine clinics. Shoulder pain can be associated with a variety of diagnoses for which physicians typically focus on identifying the patoanatomical basis that appears to be the source of the symptoms.Physiotherapists complement the patoanatomical diagnosis by investigating pain associated with movement to arrive at a functional diagnosis that can guide physiotherapy interventions [1]. The physiotherapeutic examination and assessment focus on identifying alterations in the precision of movement that may contribute to neuromusculoskeletal dysfunction and tissue irritation and thus ought to be corrected for normalizing function and achieving pain relief [2]. Accordingly, clinical physiotherapy requires strong theoretical and clinical knowledge in the science of movement and thus the academic physiotherapy curriculum includes studies of the mechanics of movement.

At Umeå University, Sweden, one of the movement science courses has the learning objectives to [2] understand and discuss the importance of movement patterns for the development of mechanical pain in the neck/shoulder region, [2] examine movement patterns and evaluate whether increases or decreases in tissue stiffness, extensibility or timing or magnitude of activity of the muscles surrounding the neck and shoulder area affects the movement pattern and [1] understand the aim and diagnostic accuracy of the examination tests, analyze the findings of the examination procedures, diagnose the movement system impairments and understand basic movement correction/ retraining.

Regarding impairments of the neck/shoulder area, nonoptimal static alignment of the trunk, scapula and the humerus, non-optimal timing and magnitude of the scapular movement or altered relative movement of the humerus relative to the scapula are possible constituting causes of pain [1]. The theoretical part of the course includes functional anatomy, biomechanics and the foundations of physical examination. The practical part of the course includes examination of alignment and movement patterns, as well as tests of stiffness, extensibility and muscle recruitment patterns.

To improve the students' skills in diagnosing and managing movement impairments, as well as their motivation to methodologically analyse which movement impairment affects the movement pattern, we include analysis of wholebody functional movements. One type of physical exercise or practice that relies heavily on functional movements is yoga. In collaboration with a local yoga teacher a selection of relevant yoga postures, so called asanas, have been included since 2014 as a course task for physiotherapy students in order to find complementary elements to improve effective learning [3].

Yoga is commonly used as complementary treatment for neck and back pain in western countries. While yoga is traditionally rooted in Indian philosophy and has been described as a means for uniting mind, body and spirit, it has also become a popular tool for promoting physical exercise and well-being. In Europe and North America, yoga is most often associated with physical postures (asanas), breathing techniques (pranayama) and meditation (dyana). There are many different schools or systems of yoga. The type of yoga practice that forms the basis for thepostures in our university-based movement science course is called Patanjali yoga. This form of yoga focuses on postural correction or alignment to increase the awareness of how the different body parts move together, how malposition of the joints can be associated with pain and sequencing of the postures. 
The use of props to support different postures is systematically acquired and requires the students to explore the basics of their therapeutical knowledge so that dysfunctional movements and injuries can be avoided. Further, the incorporation of selected yoga postures allows the students to apply their basic knowledge in anatomy, physiology, methodology and didactics in a practical context.

The instruction of the practice of asanas in the physiotherapy movement science course is led by a certified yoga teacher collaborating together with a physiotherapy teacher. They use a didactic technique, meaning that they focus on the baseline knowledge that the students possess in movement analysis and seek to improve upon and convey this information throughout the progression of the course. The yoga teacher and the physiotherapy teacher function as guides and resources for the students. For example, the yoga teacher explains the names and the meanings of the yoga postures and demonstrates the exercises. Thereafter the students work in pairs and try to determine what an optimal postural alignment and performance of the movement would entail and why the posture/movement might not be optimal/performed optimally. The yoga and physiotherapy teachers, then guide the students through the movements and postures in detail, confirming or rejecting their hypotheses [4].

During October 2014 and March 2017, data regarding the students' experiences were collected after each yoga session. All students were asked to participate in these discussions. Discussion themes included whether the integration of practicing and analyzing yoga postures had contributed to the students' skills in diagnosing movement impairments, their motivation to methodologically analyze alignment and movement, if and how the sessions might have added to their previous physiotherapy knowledge, and if or how and why they would include this knowledge in their clinical reasoning in physiotherapy practice.

The physiotherapy students' perceptions were that they had increased their competence in analyzing alignment and movement patterns and their knowledge about exercises targeting extensibility. Further, the students reported that they had improved their understanding of how to discuss posture, alignment and movement patterns with each other (and with patients in the future) by using explanations influenced by the academic yoga sessions. The students thought it was beneficial to learn both the yoga expressions and the physiotherapy Neuro musculoskeletal explanations for the yoga postures, musculoskeletal alignment and movement impairments. An important aspect that was raised was that the students had learned in previous courses that poor adherence to exercise may limit the effectiveness of prescribed exercises.
They had also read the review by the Cochrane collaboration [3] concluding that patient preference should always be considered to increase motivation to initiate and maintain the exercise program. The students considered certain yoga postures as ways to increase exercise motivation for some physiotherapy patients. Including effective yoga exercises at home-based training was suggested as a way to increase motivation for initiating and maintaining home-based exercise program. Also, since the type of exercise setting should be directed by patient preference, and yoga exercises have proven to be similarly effective as stretching-classes [5], exercises targeting extensibility for healthy individuals could be performed in yoga studios. Lastly, the physiotherapy students highly valued the opportunities for dialogue and interaction with physiotherapy teachers during the academic yoga sessions to keep a scientific physiotherapeutic perspective on the assessment and relevant integration of selected yoga exercises for patients with neuromusculoskeletal dysfunction.

To conclude, the results from the group discussions indicated that physiotherapy students could enhance their competence in supporting patients to embrace exercises targeting extensibility by integrating aspects from selected yoga movements and postures. Also, the physiotherapeutic understanding of the yoga exercises seemed to motivate the physiotherapy students to learn more about movement science. Thus, teaching in physiotherapy that incorporates theoretical and practical elements of assessing and analyzing yoga-based postures might, provided that appropriate physiotherapeutic didactic methodology and feedback is provided, improve physiotherapy students' learning and motivation in movement science. Our experiences might be of particular interest to educators in healthcare settings who can devise further inclusion of instructional learning activities.

\section{Reference}

1. Ludeweig PM, Lawerance RL, Braman JP (2013) What's in a name? Using movement system diagnoses versus pathoanatomic diagnoses. J Orthop Sports Phys Ther 43(5): 280-283.

2. Caldwell C, Sahramann S, Van dillen NL (2007) Use of a movement system impairment diagnosis for physical therapy in the management of a patient with shoulder pain. J Orthop Sports Phys Ther 37(9): 551563.

3. Jordan JL, Holden MA, Mason EE, Foster NE (2010) Interventions to improve adherence to exercise for chronic musculoskeletal pain in adults. Cochrane Database Syst Rev (1): CD005956.

4. Sahramann SA (2011) Movement System Impairment Syndromes of the Extremities, Cervical and Thoracic Spines. Elsevier, ( $1^{\text {st }}$ edn), USA pp. 568.

5. Sherman KJ, Cherkin DC, Wellman RD, Cook AJ, Hawekes RJ, et al. (2011) A randomized trial comparing yoga, stretching, and a self-care book for chronic low back pain. Arch Intern Med 171(22): 2019-2026. 
This work is licensed under Creative

Commons Attribution 4.0 License

DOI: 10.19080/JYP.2017.01.555569
Your next submission with Juniper Publishers will reach you the below assets

- Quality Editorial service

- Swift Peer Review

- Reprints availability

- E-prints Service

- Manuscript Podcast for convenient understanding

- Global attainment for your research

- Manuscript accessibility in different formats

( Pdf, E-pub, Full Text, Audio)

- Unceasing customer service

Track the below URL for one-step submission https://juniperpublishers.com/online-submission.php 